\title{
A DOUTRINA DO DIREITO NATURAL EM TOMÁS DE AQUINO
}

D. Odilão Moura*

SINTESE - Nos tempos modernos, a doutrina do direito natural tem sido negada por muitos autores. Não foi assim entre os medievais e entre os antigos. Tomás de Aquino, em diversas partes de sua obra, trata do tema e mostra como a própria racionalidade do homem o leva a descobrir algo que está insito no mais intimo de sua natureza.
ABSTRACT - The doctrine of the natural law in our times has been denied by many authors, as opposed to medieval and ancient thinkers. In several parts of his work, Thomas Aquinas deals with this subject and shows that the human reason leads everyone to discover the natural law.

Foi afirmada repetidas vezes pela tradição católica a existência de um direito natural. Não obstante ser ele negado pela generalidade dos homens de hoje, é, contudo, assunto de grande atualidade, sendo objeto de discussões entre juristas, filósofos e teólogos.

Desde o início da civilização ocidental, foi reconhecido um direito imediatamente decorrente das exigências da natureza humana, facilmente reconhecido pelos gregos, pelos romanos e pelos medievais. Essa tradição mais que milenar sofreu forte abalo no século XVI, provocado por Lutero. Este, ao afirmar a corrupção da natureza humana pelo pecado original, obviamente não aceitaria um direito fundamentado numa natureza má. Por isso, para ele, os primeiros direitos do homem procedem da palavra de Deus, revelada na Bíblia. Os primeiros direitos e deveres do homem não mais efluem espontaneamente do reconhecimento imediato das exigências da essência humana, mas serão a ela extrinsecamente acrescidos.

Respeitado pelos povos primitivos, desde a mais remota antiguidade; um direito inseparável do homem foi sendo lentamente esclarecido através da História. Sófocles, no século $\mathrm{V}$ a. C., no seu famoso texto teatral, transmite-nos as palavras de Antígona ao tirano, ao exigir ela o sepultamento do próprio irmão: "Os decretos divinos, leis não escritas e imutáveis, não são de hoje, nem de ontem, e ninguém sabe de que longínquo período procedem." Aristóteles desenvolveu uma doutrina sobre 0 direito natural, ${ }^{1}$ mais tarde retomada pelos estóicos, reassumida por Cícero,

- Mosteiro de S. Bento - Rio de Janeiro.

1 Aristóteles. Retórica I, cap. 25; Ética a Nicômaco V, cap. VII; Política I, c. 3. Cf. a respeito os respectivos comentários de Tomás de Aquino.

\begin{tabular}{|l|l|l|l|l|l|} 
VERITAS & Porto Alegre & v. 40 & $n^{\circ} 159$ & Setembro 1995 & p. $481-491$ \\
\hline
\end{tabular}


que a transmitiu aos romanos. São bem conhecidos os trabalhos dos grandes mestres romanos, Ulpiano, Justiniano e Gaio, acentuando o primado do direito natural. A rica tradição pagã a respeito foi tranqüilamente aceita pelos cristãos, que a conciliaram com os dados da Revelação. Este trabalho foi aperfeiçoado pelos canonistas e teólogos dos séculos XII e XIII.

Os grandes mestres universitários medievais dirigiram as vistas para a ciência jurídica, sobretudo a relativa ao direito natural. As lições deixadas por Isidoro de Sevilha, Graciano, Pedro Lombardo, Alberto Magno, Tomás de Aquino, Boaventura, Guilherme de Auxerre, Filipe Cancelário e por tantos outros, testemunham o elevado grau atingído pelo estudo do direito natural naqueles remotos tempos. Mais tarde, na mesma linha da tradição jurídica medieval, Vitória e Suárez trazem as suas preciosas contribuições, sendo seguidos por Bañez, Vasquez e Toledo.

O protesto luterano do século XVI, como vimos acima, deu novos rumos para a ciência do direito. Os juristas das nações evangélicas, alicerçados logicamente na doutrina da corrupção da natureza humana pelo pecado, desvincularam dela o direito natural. Negou-se, então, a noção até aquele tempo aceita, concernente à existência de um tal direito. Não haverá, para eles, um direito natural, mas um direito originado do critério humano.Na realidade, todo direito será direito positivo. Famosos mestres do direito, e até políticos, serão os formuladores da nova ordem jurídica, salientando-se, entre eles, Grotius, Puffendorf, Tomasius, Gurvitch, Thering, Kelsen. Contudo, diversos outros autores, como a personalidade impar de Del Vecchio, reafirmam a doutrina tradicionalmente consagrada.

Também os filósofos contribuíram para a negação do direito natural. Pondo o dever como um princípio da moral, dever este impulsionado por um "imperativo categórico" da vontade, Kant tirou do direito fundamental a sua formalidade racional, elemento essencial à reta noção do direito natural. A filosofia de Kant matou no direito natural o conhecimento espontâneo das suas normas e o homem passa a operar por um impulso cego do cumprimento do dever.

Outra corrente filosófica agiu da mesma forma em nosso século. Ao negar a prevalência da essência sobre a existência, mas afirmando a desta sobre aquela, o existencialismo destruiu toda e qualquer norma fixa para o homem. Sartre ensina que, moralmente, o homem é uma criação de si mesmo e as suas ações não derivam de regras preestabelecidas, mas ele mesmo, pelo seu arbitrio, as programa e as realiza. É conhecida a enorme influência do existencialismo sartreano em nossos dias, com a tese de que "o homem é um projeto", que está a todo o momento criando a si mesmo ${ }^{2}$

As linhas acima, nas quais tentamos, em traços largos, descrever a evolução da doutrina sobre o direito natural, servirão para bem situar o pensamento de Santo Tomás sobre o mesmo e apresentam os motivos, segundo os quais muitos pensadores contemporâneos ainda o têm como verdadeiro. Para estes, o direito natural não é uma peça esquecida nos arquivos das ciências jurídicas, mas mostra-se de grande atualidade. Entre os católicos, esta posição voltou a evidenciar-se, por exemplo, em documentos da Igreja, como a recente encíclica Veritatis splendor, de João Paulo II. ${ }^{3}$ Nesse documento, o Papa conceitua a natureza de tal direito e recu-

2 Sartre, J. P. L'Existencialisme est un Humanisme. Paris: Nagel, 1963. p. 23.

3 Trad. portuguesa São Paulo: Ed. Paulinas, 1993. p. 71, n. 44. 
sa as teses dos que pretendem basear os direitos humanos em dados estatísticos, ou que definem o homem como um puro projeto. É relevante, para o tema desta comunicação, observar que toda a encíclica está embasada na doutrina apresentada por Tomás de Aquino. Escreve o papa: "A Igreja referiu-se freqüentemente à doutrina tomista do direito natural, assumindo-a no próprio ensinamento da moral" $^{4}{ }^{4}$ Esta frase condensa a tradição do magistério pontifício, anteriormente ensinado por Leão XIM ${ }^{5}$ e por Pio XI, ${ }^{6}$ e transmitido nas excelentes alocuções de Pio XII durante a II Guerra Mundial. Na mesma linha mantiveram-se João XXIII e Paulo VI.

Após esta introdução, consideremos o que propriamente nos ensinou o Doutor Angélico sobre o direito natural, segundo esta ordenação:

I - Três esclarecimentos prévios

II - Fontes doutrinárias do direito natural formulado por Santo Tomás e a localização do mesmo em suas obras

III - Síntese da doutrina tomista sobre o direito natural

IV - Conclusão.

\section{I - Três esclarecimentos prévios}

Três esclarecimentos prévios são necessários para a justa compreensão do pensamento jurídico tomista, como também para o de muitos mestres medievais. Focalizando-os, serão evitadas algumas leituras que obscurecem aquela compreensão e que acarretam consigo conseqüências práticas desastrosas. Torna-se, pois, inevitável estabelecer distinção entre direito e moral, entre direito e lei, e entre direito natural e direito primitivo. Consideremo-las separadamente:

1. $O$ objeto da moral são todos os atos do homem, enquanto dirigidos para o bem de si mesmo. $O$ bem moral do homem é ele realizar-se seguindo as exigências de sua natureza. A finalidade das ações do homem é realizar-se ele perfeitamente, e isto faz que o homem se realize de forma superior à dos seres sem vida, ou à dos seres vivos sem razão. Cada ser criado existe segundo busca seu bem. $\mathrm{O}$ homem busca o seu bem agindo livremente, por ato imperado por sua vontade, que, por sua vez, segue a própria razão. A razão humana dirige o homem para que ele seja autenticamente humano. As virtudes morais levam o homem a sempre operar com perfeição. Por isso, a moral tomista é uma moral de virtudes morais, conquistadas pelo próprio homem, mas enriquecida pelas virtudes sobrenaturais e por outros dons concedidos por Deus.

$O$ objeto do direito é mais restrito que o da moral, embora subordinado a ela. As leis morais estabelecem os princípios do direito. Porém, enquanto a moral abrange o exercício de todas as virtudes, o direito não ultrapassa ao objeto da vir-

\section{id. ibid.}

5 Cf. Rerum novarum. AAS, I, p. 109.

6 Cf. Studiorum ducem (29.06.1923): "Sendo ele [Santo Tomás] o teólogo perfeito, traçou as regras certas e os preceitos de vida, não apenas para os individuos, bem como para a sociedade familiar e civil [...] Daí aqueles magníficos capítulos da Segunda Parte da Suma Teológica sobre o regime paternal ou doméstico, [...] sobre o direito natural e sobre o direito dos povos [...] Deve-se desejar que se estudem e cada vez mais os ensinamentos do Aquinate sobre o direito dos povos e sobre as leis que regulam as relações mútuas entre as naçōes" (AAS, 1923 (XV), p. 711). 
tude da justiça. Por isso, só cabe ao direito determinar o justum, isto é, aquilo que é devido em estrita igualdade ao outro. Implicando no seu exercício o outro, o sócio, o direito, como também a virtude da justiça, é essencialmente social.

As outras virtudes morais visam ao bem do próprio homem; a justiça, assim como o direito, visa o bem do outro. Já ensinava Aristóteles que "o amor une as cidades, e os que estabelecem as leis mais se preocupam com a justiça". " Seguindo a mesma trilha, escreve Santo Tomás: "A paz é indiretamente obra da justiça, diretamente, da caridade" (II-II, 29, 3, ad 3). A moral, pois, está na ordo amonis, o direito, na ordo justitiae ${ }^{8}$

A distinção entre direito e moral, e a subordinação deste àquela, vigoram não somente no plano da sociedade juridicamente estruturada dos povos civilizados, como também nos povos primitivos. Por isso, jamais o direito positivo anulará o direito natural.

Convém, para melhor apreensão do pensamento jurídico medieval, levar em consideração que Santo Tomás, como os demais mestres de seu tempo, não trataram do chamado "direito subjetivo", que hoje é muito focalizado. Eles consideraram apenas o "direito objetivo", sem contudo desconhecerem o sentido análogo da expressão "direito subjetivo".

2. A lei - lex - como norma racional de ação ("ordinatio rationis"), deve ser distinguida do direito e da moral. Os autores medievais, no entanto, usavam o termo lei como sinônimo de direito e de moral. Sto. Tomás, tão exato e formal no modo de se expressar, por vezes usa esses termos como sinônimos, não fugindo à regra costumeira dos outros mestres medievais.

Todavia, é muito claro quando estabelece a distinção entre as duas expressões, ao escrever: "A lei não é o mesmo que o direito, propriamente falando, mas uma certa razão do direito" (II-II, 51, 1 ad 2). Moral e direito implicam sentido mais amplo que o da lei. A lei propõe as normas de ação humana; a moral e o direito não somente as reconhecem, como também as aplicam às inumeráveis ações humanas.

3. A distinção entre direito natural e direito positivo vem de tradição milenar. Hoje, em geral, tal distinção não é acentuada como deveria ser, o que implica más conseqüências.

Sto. Tomás, sempre fiel às legítimas tradições, afirma a distinção entre direito natural e direito positivo, em sólido artigo da Suma Teológica (II-II 57, 2). O termo direito aplica-se aos dois direitos analogicamente, alicerçando Santo Tomás a sua distinção em Aristóteles. ${ }^{9}$ Haverá um direito proveniente "da própria natureza da coisa", direito natural, que não se confunde com as normas da justiça firmadas entre duas pessoas, ou estabelecidas pela autoridade pública (direito positivo). Enquanto o primeiro direito independe da vontade humana, o segundo nasce dela por uma convenção estabelecida.

7 Ética a Nicômaco, 1. VIII.

8 Cf. Journet, Charles. Exigences Chrétiennes en Politique. Paris, 1945. p. 216.

9 Ética V, 7, 1. 
O primeiro direito é instituido e promulgado por Deus, que possibilita ao homem, pela sua própria natureza racional, facilmente conhecê-lo, e só Deus poderá alterá-lo, mas não o faz, porque a sabedoria divina não é contraditória. O segundo direito é firmado por convenção humana, cabendo ao homem promulgá-lo, anulálo, ou modificá-lo, se necessário for. É de sua estrutura ser mutável. O direito natural é imutável, como a própria natureza do homem, visto ser elaborado pela sabedoria divina. Evidentemente, o direito positivo deve subordinar-se ao direito natural. Toda lei que contradiga as normas do direito natural é iníqua e desumana.

\section{II - Fontes doutrinárias do direito natural formulado por Santo Tomás e a localização das mesmas em suas obras}

Os estudos jurídicos, relativos ao exercício do direito e à sua história, foram intensos nos séculos XII e XIII. Canonistas e teólogos dedicavam-se atentamente àqueles estudos, interessados sobretudo na formulação de uma teoria do direito ilustrada pelos dados da Revelação.

Em nossa época, dois autores, D. Odon Lottin, $\mathrm{OSB}^{10}$ e Fr. Santiago Ramirez, $\mathrm{OP}_{1}{ }^{11} \mathrm{em}$ magistrais obras historiaram com exímia sabedoria aqueles estudos. Sto. Tomás, seguindo as pegadas dos mestres de sua época, dedicou-se também aos mesmos estudos, legando aos pósteros uma sintese doutrinária concernente ao direito natural, síntese esta ao mesmo tempo tradicional e inovadora.

Ocasionalmente discorreu sobre o direito natural em algumas de suas obras, nas quais comentava a Ética aristotélica, e em outras. Nestas, acrescentou perspectivas novas; naquelas, simplesmente explica, com sua habitual minúcia, o texto do filósofo.

Os primeiros estudos do Angélico sobre o direito natural foram exarados em lições nas quais comentou as proposições de Pedro.Lombardo sobre este direito (Cf. IV Sent. 39, 1-1). Em tais lições já se encontra esboçada, pelo jovem mestre, a teoria sobre o direito natural que, vinte anos mais tarde, ele, mestre em Paris, levará à perfeição.

Na Suma Teológica (I-II, 94) desenvolve a teoria do direito natural no contexto do tratado da lei. Nesta questão, define a lei natural segundo o sentido humano, descreve como ela é conhecida pelo homem, evidencia o seu conteúdo, do qual procedem as suas principais propriedades: unidade, imutabilidade e perenidade na alma humana.

$\mathrm{Na}$ questão 57 da II-II da mesma obra, o direito natural é focalizado no tratado de jure, abordando a sua distinção frente ao direito positivo, e a sua divisão em direito natural propriamente dito, em direito das gentes e em formas especiais (direito paterno, direito dominativo e direito doméstico).

Coligindo as proposições constantes na Suma Teológica, formular se-á uma teoria do direito natural sistemática e completa, como se exporá adiante. Porém, não será sem proveito serem aqui antecipadas três características intrínsecas à teoria tomista do direito natural, facilmente desvendadas na leitura daquelas ques-

10 Psychologie et Morale aux XI ${ }^{\circ}$. et XII' . Siècles. t. I e II. Gembloux: Ed. Duculot, 1942-1948.

11 El Derecho de Gentes. Madrid: Ed. Studium, 1955. 
tões: a fonte divina do direito natural, o sujeito humano e a formalidade racional do mesmo.

Sob o aspecto histórico-doutrinário, a fonte remota da concepção tomista de direito natural é toda a tradição jurídica do Ocidente, contido nos pronunciamentos dos mestres romanos do đireito, nas proposições de filósofos como Aristóteles e os estóicos, nas obras de teólogos, como Agostinho e Isidoro. A todos esses luminares da ciência do direito recorreu Santo Tomás, porém sempre com o seu agudo senso crítico, sempre dirigido pela conceituação que inicialmente estabeleceu para o direito natural. Buscou subsídios nos antecessores, mas a doutrina que formulou é sua.

As fontes imediatas encontram-se naqueles teólogos e canonistas que trataram do direito natural no século XII (Anselmo de Laon, Hugo de São Vítor, Abelardo, Pedro Lombardo), não podendo ser esquecido o famoso Graciano, com seu Decreto. Houve também, é lógico, a contribuição de seus contemporâneos, citando-se, entre eles, Guilherme de Auxerre e o dominicano Pedro de Tarantaise (mais tarde papa Inocêncio V), de quem discordou ao negar que a lei natural fosse um hábito (I-II $9,1 \mathrm{c})$.

Indiscutivelmente, a fonte próxima que mais contribuiu para a teoria tomista do direito natural foram as lições recebidas de Santo Alberto, em Colônia. Na obra Summa de Bono, Alberto analisa a doutrina do direito natural. A outra obra em que discorre sobre o tema foi redigida pelo discípulo Tomás de Aquino e contém as Preleções sobre a Ética a Nicômaco. Alberto apresenta sua doutrina segundo a colhera na tradição jurídica e teológica. Acentua os ensinamentos de Agostinho e de Cícero. Com senso crítico, sobretudo em perspectiva filosófica e teológica, expõe seu pensamento sobre o direito natural. Quanto ao conteúdo, o que ensinou a respeito coincide substancialmente com a síntese tomista. Não obstante, esta sintese, tão perfeitamente elaborada, supera a albertina. Contudo, segundo S. Ramirez, a formalidade filosófica com que Alberto fundamentou o direito permite que ele seja considerado o "criador" e "verdadeiro iniciador" da filosofia do direito. ${ }^{12}$

\section{III - Síntese da doutrina tomista do direito natural}

Examinadas algumas preliminares que facilitam a compreensão dos desenvolvimentos trazidos à teoria do direito na Idade Média, a seguir será exposta a doutrina do direito natural segundo Santo Tomás.

Aqueles pressupostos, porém, estão condicionados à colocação de uma indispensável observação preliminar: o reconhecimento da existência de uma natureza humana essencialmente estruturada por Deus e regida por preceitos dela originados, segundo disposição divina. O direito natural, conseqüentemente, obedece a dois princípios: o divino, por ser participação da lei eterna pela qual o Criador dirige todas as coisas, e o humano, enquanto necessariamente vinculado à criatura racional. Ampliemos estas duas noções:

1. Deus criador, sábio e providente das ações das criaturas, tudo dirige segundo normas preestabelecidas, que constituem a "lei divina" (I-II 93, 1). Para Santo

12 Ibid. p. 51. 
Tomás, no entanto, propriamente não há um direito divino, porque o direito fundamenta-se na igualdade do que é devido pelo devedor com a satisfação exigida pelo outro (isto é essencial à justiça). Não havendo possibilidade de igualdade entre o homem e Deus, disto resulta a negação de um direito divino. À exigência divina não se dá o nome de direito, mas o de fas, termo consagrado na língua latina para designá-la (Cf. II-II 57, 1 ad 3).

Como foi esclarecido anteriormente, a lei propriamente não se identifica com o direito (Cf. II-II, 571 ad 2), mas determina-lhe as normas principais. Não obstante essa distinção, Santo Tomás, por vezes, usa os termos lei e direito como sinônimos, e as expressões direito natural e lei natural como correspondentes.

Por ser a lei natural proveniente de disposição divina, eterna, ela é soberana, participando assim do absoluto poder de Deus, não cabendo ao homem modificála, anulá-la, nem desconhecê-la. O próprio Deus a promulga para todos os homens, ao torná-la por estes conhecida na sua natureza humana racional (Cf. II-II, 57, 2 ad 3). O direito natural não é apenas absolutamente soberano, como ainda imutável, pois participa da imutabilidade das normas divinas e também da imutabilidade da natureza humana. Por isso, concluirá o Angélico: "Se alguma coisa por si mesma se opõe ao direito natural, a vontade humana não a pode tornar justa, como, por exemplo, se for determinado ser lícito furtar ou cometer adultério" (Cf. I-II 57, 2 ad 3).

Conseqüência evidente da inclusão do direito natural na lei eterna é ser ela verdadeira. Ora, a verdade é a correspondência absoluta entre o conhecimento humano e o objeto conhecido. As coisas conhecidas pelo homem são verdadeiras, porque ele as conhece segundo Deus as programou e lhes deu a existência. Dessa veracidade participa o direito natural. Escreve o Angélico: "O intelecto divino é a medida das coisas, porque cada coisa é verdadeira enquanto imita o intelecto divino. Ora, o intelecto divino é em si mesmo verdadeiro, e a sua razão é a própria verdade" (Cf. I-II 93, 1).

Essas palavras justificam por que o pensamento cristão defende com tanta insistência a vigência do direito natural na sociedade moderna, que hoje dele se vai afastando. Nesta linha dizia o papa João XXIII: "No mais íntimo do ser humano, o Criador imprimiu uma ordem que a consciência humana descobre e manda observar estritamente. Os homens mostram que os preceitos da lei estão escritos nos seus corações, sendo sua consciência testemunha disso (Rom. 2, 15). Por outro lado, como poderia ser de outro modo? Todas as obras de Deus são, com efeito, um reflexo da sua sabedoria infinita, reflexo tanto mais luminoso quanto maior é o grau absoluto de que gozam". ${ }^{13}$

2. Ao se focalizar a lei natural, deve-se primeiramente mostrar a distinção entre ela e a lei eterna. Enquanto uma tem por sujeito a mesma natureza divina, porque as ações divinas efluem diretamente da substância de Deus, e com ela se identificam - a substância divina é operativa por si mesma - a lei natural tem por sujeito um acidente da substância do homem, a sua inteligência. É ato desta inteligência, enquanto se inclina para as coisas práticas, isto é, da ratio practica. Não

13 Enc. Pacem in temis., n. 5. 
consiste em uma disposição habitual da razão prática, mas nos atos da mesma. Santo Tomás nega assim a tese de Pedro de Tarantaise, que reduzia a lei natural a um hábito (I-II 94, 1c), como anteriormente lembramos.

É a nota "intelectiva", "racional", que caracteriza fundamentalmente no homem a lei natural e o conseqüente direito natural, visto ser o homem, antes de mais nada, um ser racional.

Santo Tomás insiste fortemente na nota racional da lei natural e toda a sua teoria deste direito está nela embebida. O direito natural é humano porque decorrente do conhecimento que o homem tem dele. Lê-se na Suma Teológica: "Como no homem a razão domina e impera sobre as outras potências, convém por isso que todas as inclinações naturais pertencentes às outras potências sejam ordenadas segundo a razão. Assim sendo, entre todos é chamado de reto o que segundo a razão sejam dirigidas todas as ações do homem " (I-II 94, 4 ad 3).

Por ser racional, o direito natural, informado que é pelas leis naturais, diferencia-se do direito da natureza, que regula as ações condicionadas pela estimativa dos animais. Não sendo especificamente racionais as "leis" que ordenam a vida dos brutos não serão propriamente chamadas de leis, mas só analogamente, por semelhança (I-II 91, 3 ad 2).

A inteligência prática que opera na lei natural implica o ato da vontade, mas a inteligência especulativa, cujo objeto é a verdade absoluta enquanto conhecida, desligada da vontade, limita-se ao puro conhecimento da verdade (I-II 94, 4C).

Ao conhecer espontaneamente o que deve fazer segundo a exigência de sua natureza, o homem, neste ato intuitivo, recebe a proclamação da lei natural. Assim sendo, ela lhe é proclamada indiretamente por Deus, que o dotou de tal capacidade. Não seja esse conhecimento confundido com o das "idéias inatas" cartesianas. Não. É a própria luz do conhecimento intelectivo que o faz evidente. Os conceitos, as idéias que a evidenciam surgem da ação intelectiva humana (II-II $57,3 \mathrm{c}$ ). ${ }^{14}$

3. Firmado o direito natural como intrinsecamente divino e humano, Santo Tomás analisará sua definição, sua divisão e as suas propriedades. São três esclarecimentos que vão completar o pensamento de Santo Tomás, relativo àquele direito, que facilmente são inferidos da doutrina exposta até aqui.

Não se encontra em Santo Tomás uma definição lógica do direito natural, segundo gênero e diferença específica. Por ser identificado com a lei natural, ${ }^{15}$ por decorrer da virtude da justiça e, de certo modo, identificar-se também com a lei divina, a definição de um conceito tão complexo não será facilmente encontrada. Ademais, o direito natural vincula inseparavelmente a si o homem individualmente e a sociedade dos homens. Não obstante as dificuldades para se descobrir uma definição estrita do direito natural, não será fora de propósito estender a ele a definição que Santo Tomás fornece de lei natural: "o conhecimento naturalmente dado

14 Parece que se equivoca Jacques Maritain ao tomar esse conhecimento por simples criatividade (cf. Soria OP, Carlos. Tratado de la Ley en General - Suma Teológica. vol. VI. Madrid: BAC, 1956. p. 116, nota). A fonte última do direito natural é a iluminação recebida de Deus: "A luz da razão natural, pela qual nós discemimos o que é bem e o que é mal, que deriva da lei natural, não é outra coisa que a impressão da luz divina em nós" (I-II 91, 2c).

Cf. Urdanoz OP, Teófilo. Tratado de Justicia. Suma Teológica. Madrid: BAC, 1956, vol. Vill. p. 184ss. 
ao homem, pelo qual ele é dirigido para convenientemente operar nas ações que lhe são próprias" (IV Sent. 33,1). ${ }^{16}$

Santo Tomás estabelece uma distinção nítida ao propor a divisão do direito natural em duas ordens: a do direito natural estritamente dito e a do "direito das gentes". Na primeira ordem, identificam-se as normas do direito natural com as exigências da natureza dos animais (II-II, 57, 3); na segunda, constituída pelas normas de ação deduzidas dos primeiros principios da lei natural, conhecidos por todos os homens, situa-se o direito das gentes. Aqui já aparece algo de direito positivo, algo "posto" pelo homem (II-I 57, 3). Exemplificando: que a terra pertença a todos os homens, porque será impossivel a todos sobreviverem sem dela tirarem os meios de sobrevivência, é norma do direito natural primário. Há "comunismo" pleno quanto à posse da terra. Como, porém, não será possível aos homens tirarem da terra 0 necessário para a sua sobrevivência, a não ser nela operando ordenadamente, tendo cada um uma porção dela, a propriedade individual é norma do direito natural secundário, ou seja, do direito das gentes. Paradoxalmente, o direito de propriedade origina-se do direito à terra comum a todos. Por isso, em casos extraordinários, para se salvar a sobrevivência dos homens, o direito natural primário prevalece sobre o direito secundário, ou direito das gentes. Note-se que ambos os direitos são próprios da natureza humana, mas em sentido análogo.

$\mathrm{Na}$ consideração histórica da vida social, nem sempre é fácil estabelecer com exatidão as áreas do direito natural primário, do direito das gentes e do direito positivo. Escreve, a respeito, Jacques Maritain: "Pois é a própria lei natural que pede que ela mesma deixe indeterminado o que seja ulteriormente determinado, seja como um direito, ou como um dever existente para todos os homens, em razão de um estado de fato estabelecido, seja como um direito ou um dever existente para alguns, devido às regulamentações humanas próprias à comunidade das quais fazem parte" ${ }^{17}$ Assim sendo, todo direito encontra o seu fundamento no direito natural, de modo especial o direito das gentes que a ele está mais fortemente vinculado. A respeito disto, o grande mestre do tomismo contemporâneo, Santiago Ramirez, indiscutivelmente o mais abalizado esclarecedor do direito das gentes, assim se pronuncia: "Sendo este própria e principalmente natural por estar contido nas conclusões imediatas dos primeiros principios da syndéresis, e não propriamente positivo, por não se derivar de lei natural à maneira de simples determinação ou

16 Com sua peculiar precisão, o filósofo Jacques Maritain apresenta uma bela conceituação do direito natural: "Suponho que admitis que há uma natureza humana, e que esta natureza humana é a mesma em todos os homens. Suponho que também admitis que o homem é um ser dotado de inteligência e como tal opera compreendendo o que faz e, portanto, tendo o poder de determinar-se a si mesmo para os fins que persegue. De outro lado, tendo sua natureza, estando constituido assim, o homem tem evidentemente fins que correspondem à sua constituição natural e que são os mesmos para todos... Mas porque o homem é dotado de inteligência e determina pard si os seus fins, cabelhe ajustar a si mesmo os fins necessariamente exigidos pela natureza. Isto quer dizer que há, em virtude da própria natureza humana, uma ordem ou disposição que a razão humana pode descobrir e segundo a qual a sociedade humana deve agir para ajustar-se aos fins necessários do ser humano. A lei não escrita, no direito natural, outra coisa não é a não ser isto. Os grandes filósofos da antiguidade sabiam, e melhor ainda sabiam os pensadores cristãos, que a natureza deriva de Deus e que a lei não escrita deriva da lei eterna que é a própria sabedoria criadora" (Maritain, Jacques. Les Droits de l'Homme et la Loi Naturelle. New York: Ed. Maison de France, 1942. p. 79s).

17 Ibid. p. 91. 
aplicação, [...] é evidente que as condições ou propriedades do direito das gentes são exatamente as mesmas do direito natural correspondente às referidas condições". ${ }^{18}$

4. Dado o conceito de direito natural, enquanto divino e humano, espontânea e diretamente surgirão as propriedades primeiras desse direito, encontradas também na lei natural. Santo Tomás as reduz a três, por serem as mais evidentes: unidade, imutabilidade e inamissibilidade. Nos tratados de Teologia Moral encontram-se outras, mas essas três são as fundamentais e as outras delas procedem. Tentemos descrevê-las.

A unidade do direito natural logo é conhecida porque ele em todos os seus preceitos se reduz ao primeiro princípio da lei natural, evidente "por si mesmo", embora sejam muitos (I-II 94, 2 ad 1). Este direito também é uno porque, distribuindo-se em todos os homens, cada homem o concebe identicamente. Por isso é universal, deve ser conhecido e praticado por todos os homens, em todos os tempos e em todos os lugares: semper et ubique. É evidente que sendo uma só a espécie humana que se multiplica nos indivíduos humanos, o bem visado por essa espécie é o mesmo para todos aqueles indivíduos, isto é, operar segundo as exigências da natureza (II-I 5,4 ad 3 ).

Sendo unitária a natureza do direito natural, conseqüentemente só pode ser imutável: "Não varia no tempo, mas permanece imutável", diz Santo Tomás (I-II 94, 5). Verifica, no entanto, o grande mestre, ser possivel dupla mudança nele: por "adição", acréscimos que o acompanham para maior exatidão, acidentalmente, feitos pelo direito positivo divino ou humano; por "subtração" (sem atingir os primeiros princípios), quanto aos princípios secundários, ou seja, do direito das gentes. Santo Tomás, no entanto, acrescenta esta ressalva:"Em algum caso particular, e isto para poucos, devido a causas especiais que impedem a observação de tais preceitos" (I-II 94, 5c). Dá-se esta variação por subtração, por exemplo, quando não se deva entregar uma arma ao seu dono, por estar louco. No caso, a prudência prevalece sobre a justiça. Com a sua costumeira clarividência, Santiago Ramirez justifica tal procedimento: "O que varia, pois, e parece que se evidencia, é a matéria a que aplicar a justiça e o direito, por ser ela variável e mutável ao teor das conđições ou circunstâncias particulares dos indivíduos; mas a justiça mesma e o direito permanecem imutáveis e conservam sempre o seu valor, por serem naturais e intrinsecamente tais". ${ }^{19}$ Salva-se então a ratio justitiae que implica sempre agir razoavelmente (cf. I-II 94, 4c).

Vinculado inseparavelmente à natureza humana, o direito natural, como ela, é inamissivel. Não é possivel apagá-lo no coração do homem quanto aos seus principios primários. Contudo, quanto aos princípios secundários, poderá desaparecer da mente humana, "seja devido às más persuasões [...], seja devido aos costumes pervertidos e pelos hábitos corrompidos, como em alguns povos não foram considerados pecados os roubos e os vícios contra a natureza, segundo diz o Apóstolo in Rom 1, 24 (I-II 94, 6c)". Nem Deus poderá apagar a lei natural da mente humana, visto que Deus não se contradiz: não substitui o bem pelo mal, nem a verdade pelo erro. Por isso, o Angélico afirma categoricamente: "Nenhum costume poderá ter

Id. ibid. p. 128. 
força de lei contra a lei divina, ou contra a lei natural" (I-II 97, 3c). E ainda: "A lei escrita não dá força à lei natural e, assim sendo, não lhe pode diminuir ou tirar a força, até porque nem a vontade do homem pode modificar a natureza" (II-II 60, 5 ad 1).

\section{IV - Conclusão: Principais características da doutrina do direito natural formulada por Santo Tomás}

Concluir-se-á, do que até aqui foi exposto em termos gerais sobre a teoria do direito natural, elaborada por Santo Tomás de Aquino, que o máximo mestre medieval arquitetou uma completa doutrina atinente àquele direito, não destituída de originalidade. Difícil ser encontrada em outro mestre do direito um corpo doutrinário referente ao tema, exposto com tanta propriedade, plenitude, perfeição e coerência.

Verificar-se-á, em primeiro lugar, que o Angélico deu à sua sistematização do direito um sentido fortemente tradicional e corajosamente inovador. Aliás, assim operava ao se articular em todos os ramos do saber. Uniu num só corpo doutrinário as lições de direito de Aristóteles, de Cícero e Gaio, com as de Graciano e Alberto Magno. Mas sempre, nesse trabalho de compilação dos ensinamentos dos antigos e modernos, ressalta a presença do discernimento tomista.

É notável que ao formular a sua teoria jurídica, o grande teólogo Tomás de Aquino não trabalha como teólogo, mas tão somente como filósofo. Rarissimamente, no corpo doutrinário jurídico, Tomás de Aquino cita a Sagrada Escritura, e ao referir-se aos mestres católicos, alguns dos quais eminentes teólogos, os vê tão somente enquanto mestres do direito. $\mathrm{O}$ direito natural, concebido pelo Angélico, é exclusivamente natural, prescindindo da revelação. Em outro tratado da Suma Teológica irá considerar o direito positivo divino, desenvolvendo-o em dez longas questões, referentes à lei divina (I-II 98-108). Propriamente, o pensamento tomista sobre o direito natural afasta-se da vinculação com a religião, e se limita a ligá-lo a Deus enquanto Criador, não enquanto conhecido e amado devido aos mistérios revelados.

Embora sempre mergulhado no amor de Deus, o nosso teólogo sabia respeitar a propriedade de cada ramo do saber, não confundindo saber filosófico com saber teológico. Por isso, ao especular, como filósofo, sobre o direito, Tomás de Aquino acentua fortemente a natureza intelectiva do direito, pois esse direito é, no homem, essencialmente, obra da inteligência.

Não teria podido Santo Tomás construir o seu sistema jurídico se não fosse dotado de um agudo senso crítico filosófico, jurídico e histórico, afastando daquele sistema claro e coerente tudo o que destoasse da verdade. As formulações tomistas, em todos os ramos do saber, partiam sempre de um princípio muito próprio do grande doutor: "Não pertence à perfeição de minha inteligência o que tu queiras ou o que tu entendas, ao conhecer, mas somente o que possui a verdade da coisa" (I 107, 2c).

A contribuição de Santo Tomás para a ciência do direito e para a filosofia do direito o situa entre os maiores mestres de todos os tempos. 